\title{
The Relation of Intrapartum Amniotic Fluid Index to Perinatal Outcomes
}

\author{
Intrapartum Amniyos SIvısı İndeksinin Perinatal Sonuçlarla Ilișkisi
}

\author{
Kahraman Ülker', İsa Aykut Özdemir² \\ ${ }^{1}$ Kafkeas University School of Medicine, Department of Obstetrics and Gynecology, Kars, Turkey, ${ }^{2}$ Dr. Sadi Konuk Education and Research \\ Hospital, Department of Obstetrics and Gynecology, Istanbul, Turkey
}

\begin{abstract}
AIM: To gradate and classify the severity of decreased amniotic fluid index (AFI) in term parturients in relation with intrapartum and perinatal outcomes.

METHODS: Term parturients $(n=700)$ with intact amniotic membranes were studied in four amniotic fluid index (AFI) groups: 1) $3 \mathrm{~cm} \leq A F I$; 2) $3 \mathrm{~cm}<A F I \leq 5 \mathrm{~cm}$; 3) $5 \mathrm{~cm}<A F I \leq 8 \mathrm{~cm}$ and 4) $8<A F I \leq 24$ $\mathrm{cm}$. Demographic, physical and ultrasonographic findings and perinatal outcomes were analyzed.

RESULTS: AFI decreased by the advancing gestational age. Advancing severity of the decreased AFI levels correlated strongly with the increased rates of cesarean birth, meconium in the amniotic fluid, abnormal fetal hearth rate trace findings, fetal distress and the post date pregnancies. The demographics and the initial cervical examinations were unrelated with the AFI measurements.

CONCLUSION: In low risk pregnancies advancing severity of the decrease in amniotic fluid volume, gestational age dependent or not, increases the ratios of pathological fetal hearth rate trace changes, diagnosis of fetal distress and the fetal distress indications which lead to cesarean deliveries. The AFI of $\leq 3 \mathrm{~cm}$ influences negatively the 1st minute Apgar score.
\end{abstract}

Key words: labor and delivery, antenatal care and diagnosis, fetal monitoring, amniotic fluid index, perinatal outcome, oligohydramnios,

intrapartum ultrasonography

\section{ÖZET}

AMAÇ: Miadında gebelerde azalmıș amniyos sıvısı indeksini intrapartum ve perinatal sonuçlarla ilișkilendirerek derecelendirmek ve sınıflamak

YÖNTEM: Miadındaki gebeler ( $n=700)$ amniyos sıVısı indeksi (ASI) gruplarının 1) $3 \mathrm{~cm} \leq A S I$; 2) $3 \mathrm{~cm}<A S I \leq 5 \mathrm{~cm}$; 3) $5 \mathrm{~cm}<A S I \leq 8 \mathrm{~cm}$ and 4) $8<A S I \leq 24 \mathrm{~cm}$ olmasına göre incelendiler. Demografik, muayene ve ultrasonografi bulguları ve perinatal sonuçlar analiz edildi.

Kahraman Ülker, Kafkeas University School of Medicine, Department of Obstetrics and Gynecology, Kars, Turkey,

Tel.05055700574Email.kahramanulker@hotmail.com

Gelis Taribi: 19.04.2011 • Kabul Taribi: 09.06.2011
BULGULAR: ASI ilerleyen gebelik haftasıyla birlikte azaldı. ASI azalmasının șiddetlenmesi Sezaryen doğum, amniyos sıvısında mekonyum, fetal kalp hızı traselerinde anormal bulgu, fetal distress ve miad așımı oranlarının artıșlarıyla güçlü korelasyonlar gösterdi. Demografik bulgular ve bașlangıç servikal muayene bulgularıly ASI arasında ilișki saptanmadı.

SONUÇ: Düșük riskli gebelerde amniyos sıvısı hacminin azalması, gebelik yașına bağlı ya da bağımsız, patolojik fetal kalp hızı bulguları, fetal distress tanısı ve fetal distress tanılı sezaryen doğum oranlarını arttıır. ASı $\leq 3 \mathrm{~cm}$ olduğunda 1. dakika Apgar skoru da olumsuz etkilenir.

Anahtar kelimeler: doğum eylemi ve doğum, antenatal bakım ve tanı, fetal monitorizasyon, amniyos sIvısı indeksi, perinatal sonuçlar, oligohidramniyos, intrapartum ultrasonografi

The detection of antepartum or intrapartum oligohydramnios has been reported to increase the risks of meconium stained amniotic fluid, abnormal fetal heart rate traces, and fetal distress related operative deliveries $^{1-9}$. A significant decrease of amniotic fluid volume (AFV) below $1 \mathrm{~cm}$ detected by using the approach of vertical measurement of the deepest amniotic fluid pouch has also been defined as abnormal for biophysical profile studies ${ }^{6}$. Several studies have demonstrated the negative effects of oligohydramnios on postterm pregnancy outcomes ${ }^{9-12}$ and a frequent association with intrauterine growth restriction (IUGR) $)^{9,13-15}$. Nevertheless, other researchers have found oligohydramnios associated with IUGR to be a poor predictor of peripartum complications $^{16}$.

The Amniotic Fluid Index (AFI), which was designed by Phelan and better reflects the intrauterine content, seems to be more advantageous than the measurement of the single deepest amniotic fluid pouch ${ }^{17}$. However, there are contradictory studies 
emphasizing the result of AFI measurement which causes more interventions in comparison to the single deepest pocket technique ${ }^{18,19}$. Some authors have even concluded that no improvement in the perinatal outcome was achieved even when AFV was determined in patients in early labor ${ }^{20}$.

According to Sarno, in pregnancies with an AFI less than $5 \mathrm{~cm}$, the chances of fetal distress related cesarean deliveries and low $1^{\text {st }}$ minute Apgar Scores increase $^{3}$. However, an AFI of less than $5 \mathrm{~cm}$ is below the $1^{\text {st }}$ percentile of normal pregnancy between 37 43 weeks ${ }^{21}$.

Previous studies have stated that a decreased AFI increases the incidence of meconium stained amniotic fluid and the number of cesarean deliveries complicated by fetal distress ${ }^{3,5,22}$. However, the pregnant groups included in these studies were relatively small and also included both pregnancies with uncompleted fetal maturity and pregnancies that could interfere with neonatal outcomes.

In one well-conducted study, researchers were unable to identify pregnancies at risk of an adverse outcome using AFV measurements taken by AFI and the single deepest vertical pocket measurement ${ }^{23}$. In order to further investigate these conflicting facts, we decided to study AFI in a low risk term pregnancy group. We hypothesised that increasing severity of oligohydramnios in pregnant women with intact membranes would increase the rates of fetal distress and cesarean deliveries.

\section{Materials and Methods}

The study was performed in Bakırköy Maternity, Women's and Children's Health Educational Hospital /Istanbul. Pregnant women $(\mathrm{n}=700)$ evaluated in the active phase of labour with intact amniotic membranes were included in this prospective observational study. Gestational age was established by the first date of the last menstrual period and confirmed by first trimester sonography. Exclusion criteria included the rupture of membranes, and maternal or fetal complications. Maternal complications included hypertensive pregnancy disorders, gestational or pre-gestational diabetes, maternal vascular disease, and any known chronic illness. Fetal complications included rupture of membranes, congenital malformations, IUGR, and prematurity $\left(<36^{\text {th }}\right.$ gestational week)
AFI was measured within the first 30 minutes of hospitalization. Information about the demographics, gestational history, and the women's health history was obtained. AFI measurements followed vaginal digital examination and 20 minute fetal heart rate tracings.

AFI measurements were performed with a real time ultrasound instrument (Toshiba Sonolayer SSA $270 \mathrm{~A}$ ) equipped with a $3,5 \mathrm{mHz}$ linear array transducer. All measurements were performed according to the "four quadrants technique" defined by Phelan and collegues ${ }^{24}$. According to the measurement of AFI, four groups were formed as: AFI $\leq 3 \mathrm{~cm}$ (severe oligohydramnios), $3 \mathrm{~cm}<\mathrm{AFI} \leq 5 \mathrm{~cm}$ (oligohydramnios), $5 \mathrm{~cm}<\mathrm{AFI} \leq 8$ (borderline oligohydramnios) and $8 \mathrm{~cm}<\mathrm{AFI} \leq 24 \mathrm{~cm}$ (normal AFI). Women with an AFI of more than $24 \mathrm{~cm}$ were excluded from the study.

A 20 minute long fetal heart rate and tocodynamometer trace record was obtained for each hospitalized woman. Standards defined by Freeman and Collegues $^{25}$ were used for the assesment of fetal heart rate and tocodynamometer traces. Followup fetal heart rate traces were recorded with one hour intervals, until all findings remained normal. Amniotomy was performed when the servical dilatation was $5 \mathrm{~cm}$ or more to qualify the amniotic fluid. Mode of delivery and indications for cesarean delivery were recorded. Pregnant women who had received oxytocine, either for the purposes of induction or augmentation of labor, were excluded from the study.

Neonatal outcomes were analysed by $1^{\text {st }}$ and $5^{\text {th }}$ minute Apgar scores.

Statistical analyses were performed using SPSS version 16.0 software (SPSS Inc, Chicago, IL). One way analysis of variance (ANOVA) and Pearson's correlation tests were used in statistical analysis. A $P$ value $<0.05$ was considered statistically significant.

\section{Results}

The demographics and the distrubution of the pregnant women among the four groups are summarised in Tables I and II.

Although cervical dilatation and effacement were higher in women with an AFI higher than $5 \mathrm{~cm}$, they did not correlate with AFI measurements ( $p>0.05)$. 
The pregnant women were compared according to their gestational weeks during delivery (Table III). Elongation of the pregnancy beyond 42 weeks caused a significant decrease in AFI measurements and a significant increase in cesarean delivery rates $(\mathrm{p}<0.05)$.
Fetal heart rate traces were evaluated as "normal" in $582(83,1 \%)$ of the pregnant women. There were variable decelerations in $84(12 \%)$, late decelerations in $14(2 \%)$, decrease or loss of beat to beat variability in $13(1,8 \%)$, fetal tachycardia in $3(0,4 \%)$, and fetal bradycardia in $4(0,6 \%)$ of the traces.

Table 1. The summary of the demographics and the physical findings during hospital admission.

\begin{tabular}{lcc}
\hline $\mathrm{N}=700$ & Mean \pm Standard deviation & Median (Minimum-Maximum) \\
\hline Maternal Age (Years) & $24.91 \pm 4.66$ & $24(16-40)$ \\
Gravidity & $1.98 \pm 1.27$ & $2(1-11)$ \\
Parity & $0.69 \pm 0.88$ & $0(0-5)$ \\
Miscarriages & $0.19 \pm 0.47$ & $0(0-3)$ \\
Induced abortions & $0.10 \pm 0.33$ & $0(0-3)$ \\
Ectopic pregnancy & $0.01 \pm 0.08$ & $0((0-1)$ \\
Amniotic fluid index (cm) & $11.00 \pm 4.62$ & $11(0-24)$ \\
Cervical dilatation (cm) & $3.54 \pm 1.43$ & $3(1-8)$ \\
Cervical effacement $(\%)$ & $60.10 \pm 14.09$ & $60(10-100)$ \\
\hline
\end{tabular}

Table 2. The summary of the comparison of the four study groups. The data were presented as mean \pm standard deviation* or median**.

\begin{tabular}{|c|c|c|c|c|c|}
\hline & $\begin{array}{c}A F I>8 \mathrm{~cm} \\
\mathrm{~N}=534(76 \%)\end{array}$ & $\begin{array}{c}8 \mathrm{~cm} \geq \mathrm{AFI}>5 \mathrm{~cm} \\
\mathrm{~N}=69(10 \%)\end{array}$ & $\begin{array}{c}5 \mathrm{~cm} \geq A F I>3 \mathrm{~cm} \\
\mathrm{~N}=57(8 \%)\end{array}$ & $\begin{array}{c}3 \mathrm{~cm}>\mathrm{AFI} \\
\mathrm{N}=40(6 \%)\end{array}$ & $\mathrm{p}$-value \\
\hline Maternal Age (Years) ${ }^{\star}$ & $24.85 \pm 4.83$ & $24.39 \pm 3.57$ & $25.46 \pm 4.45$ & $25.87 \pm 4.26$ & 0.329 \\
\hline Gravidity** & 2 & 2 & 2 & 2 & 0.746 \\
\hline Parity** & 0 & 1 & 1 & 1 & 0.630 \\
\hline Miscarriages $^{\star \star}$ & 0 & 0 & 0 & 0 & 0.076 \\
\hline Induced abortions ${ }^{\star \star}$ & 0 & 0 & 0 & 0 & 0.880 \\
\hline Ectopic pregnancy ${ }^{\star \star}$ & 0 & 0 & 0 & 0 & 0.647 \\
\hline $\mathrm{AFI}(\mathrm{cm})^{\star}$ & $12.80 \pm 3.59$ & $7.29 \pm 0.77$ & $4.68 \pm 0.47$ & $2.30 \pm 0.85$ & 0.000 \\
\hline Cervical dilatation $(\mathrm{cm})^{\star}$ & $3.50 \pm 1.48$ & $4.46 \pm 0.92$ & $3.24 \pm 1.37$ & $2.90 \pm 0.59$ & 0.000 \\
\hline Cervical effacement $(\%)^{*}$ & $60.13 \pm 14.42$ & $65.07 \pm 7.79$ & $56.49 \pm 17.47$ & $56.25 \pm 9.52$ & 0.001 \\
\hline
\end{tabular}

Table 3. The comparison of the pregnant women according to the gestational weeks during delivery. The data were presented as mean \pm standard deviation ${ }^{*}$ or median**.

\begin{tabular}{|c|c|c|c|c|}
\hline & $\begin{array}{c}36 \leq \mathrm{GW} \leq 40 \\
\mathrm{~N}=597(85 \%)\end{array}$ & $\begin{array}{l}40<\mathrm{GW} \leq 42 \\
\mathrm{~N}=79(11 \%)\end{array}$ & $\begin{array}{c}42<\mathrm{GW} \\
\mathrm{N}=24(4 \%)\end{array}$ & $\mathrm{p}$-value \\
\hline Maternal Age (Years) ${ }^{\star}$ & $24.76 \pm 4.56$ & $25.48 \pm 5.02$ & $26.75 \pm 5.65$ & 0.063 \\
\hline Gravidity ${ }^{\star \star}$ & 2 & 2 & 2 & 0.401 \\
\hline Parity** & 0 & 1 & 1 & 0.228 \\
\hline Miscarriages ${ }^{\star \star}$ & 0 & 0 & 0 & 0.632 \\
\hline Induced abortions ${ }^{\star \star}$ & 0 & 0 & 0 & 0.359 \\
\hline Ectopic pregnancy ${ }^{\star \star}$ & 0 & 0 & 0 & 0.121 \\
\hline $\mathrm{AFI}(\mathrm{cm})^{*}$ & $11.22 \pm 4.34$ & $10.49 \pm 6.18$ & $7.12 \pm 3.60$ & 0.000 \\
\hline Cervical dilatation $(\mathrm{cm})^{\star}$ & $3.50 \pm 1.40$ & $3.68 \pm 1.59$ & $4.12 \pm 1.39$ & 0.069 \\
\hline Cervical effacement (\%) & $59.98 \pm 13.66$ & $60.38 \pm 16.98$ & $62.08 \pm 14.44$ & 0.761 \\
\hline Cesarean Delivery $(\%)^{\star}$ & $0.08 \pm 0.27$ & $0.13 \pm 0.33$ & $0.29 \pm 0.46$ & 0.001 \\
\hline
\end{tabular}


Amniotic fluid was observed as clear, meconium stained, or blood stained in $610(87,1 \%), 81(11,6 \%)$ and $9(1,3 \%)$ of the pregnant women during amniotomy.

$634(90,6 \%)$ of the women had vaginal deliveries and $66(9,4 \%)$ cesarean. The indications for cesarean delivery were as follows: $22(33,3 \%)$ fetal distress, $14(21,2 \%)$ arrest of labor progression, $14(21,2 \%)$ cephalo-pelvic disproportion, $2(3 \%)$ uterine anomaly, $5(7,6 \%)$ fetal macrosomia, $2(3 \%)$ breech presentation, $3(4,5 \%)$ fetal distress and arrest of labor progression, $1(1,5 \%)$ fetal distress and cephalo-pelvic disproportion, and $1(1,5 \%)$ fetal macrosomia and breech presentation.

Correlation analysis showed that AFI correlated negatively with the cesarean delivery rate, gestational week, abnormal fetal heart rate trace findings, meconium staining of the amniotic fluid, diagnosis of fetal distress, and the post-date pregnancy rates $(\mathrm{p}<0.05)$. The correspondence of AFI to cesarean delivery, meconium staining, abnormal fetal heart rate trace findings, and the fetal distress rates are represented in Figure 1. The association of AFI to the Apgar scores are represented in Figure 2.

\section{Discussion}

We observed that the severity of diminished AFV increased the chance of intrapartum abnormal findings. However, it affected only the mode of delivery and the $1^{\text {st }}$ minute Apgar scores in the deliveries associated with fetal distress.

The aim of intrapartum assesment of fetal well-being is to identify those fetuses at high risk. For this reason, the results of obstetricians' amniotic fluid studies are not surprising since amniotic fluid volume measurement is an indirect indicator of fetoplacental function ${ }^{10,26}$. An instance of this is hypoxemia where a disturbance in renal perfusion ${ }^{27}$ and decreasing fetal urine production results in a decrease in the amiotic fluid levels ${ }^{26}$.

Prior to the advent of ultrasonograhy, amniotic fluid volume measurements could only be obtained invasively by dye dilutional methods. However, this was not practical in clinical usage. In 1933, by injecting a specific amount of Congo Red into amniotic fluid, a dye dilution method was used ${ }^{28}$. Following the injection of Congo Red, amniotic fluid was obtained a few minutes later for spectrophotometric analysis to calculate the total volume. Later, scores of investigators reproduced similar studies by using different substances instead of Congo Red.

With the advent of ultrasound, amniotic fluid could be measured non-invasively. At first, AFV measurements were dependent on non-quantitative observations. For example, some authors ${ }^{9}$ predicted amniotic fluid as normal when no ecogenic areas were seen between the uterine wall and the fetal body or the extremities. Other investigators tried to predict perinatal outcomes by measuring fluid pouch sizes. Amniotic fluid pouch size at levels of $0,5 \mathrm{~cm}^{8}, 1$ $\mathrm{cm}^{1,11,13,21}$ and $3 \mathrm{~cm}^{10,29}$ were used as an indicator of decreased amniotic fluid by some authors.

In 1987, Phelan et al. described a new method for amniotic fluid volume measurement ${ }^{24}$. They divided the uterine cavity into 4 quadrants and added the measurement of the size of the largest pouch in each quadrant. A level below $5.1 \mathrm{~cm}$ was described as oligohydramnios. Jeng et al. ${ }^{30}$ demonstrated that amniotic fluid levels below $8.1 \mathrm{~cm}$ represented levels below 5\% during the third trimester gestational age. Moore and Cayle ${ }^{21}$ prospectively studied the AFI in 791 pregnant women, specifying the gestational age. Rather than using a snap-shot measurement, their approach was probably more objective. Compatible with their results, the AFV levels in our study decreased gradually with an increase in gestational age.

In another study, the indication for cesarean delivery of fetal distress increased in $11 \%$ of the pregnant women with an amniotic fluid level below $5.1 \mathrm{~cm}^{2}$. However, the AFV measurements were performed 7 days before the delivery. Baron et al. ${ }^{22}$ found the increase rate to be $4,1 \%$; however, their study population included all pregnancies of $\geq 26^{\text {th }}$. gestational weeks. In a study by Sarno et al. $^{3}$ conducted on 17 pregnant subjects with an amnniotic fluid index below $5.1 \mathrm{~cm}$, fetal distress indication led to cesarean deliveries in $17.6 \%$ of the women. However, the size of their study group was relatively small. Robson et al. ${ }^{5}$, in their study, had to perform cesarean deliveries in 8 of 14 pregnant women with an AFI less than $6,3 \mathrm{~cm}$. However, all their subjects were in active labor and all membranes had been ruptured during AFI measurements.

Our study included low risk pregnancies of more than 36 weeks with intact membranes. Amniotomy was performed at $5 \mathrm{~cm}$ servical dilatation level. In this low risk pregnant group, we observed that a decrease in AFI was strongly correlated with an increase in the 


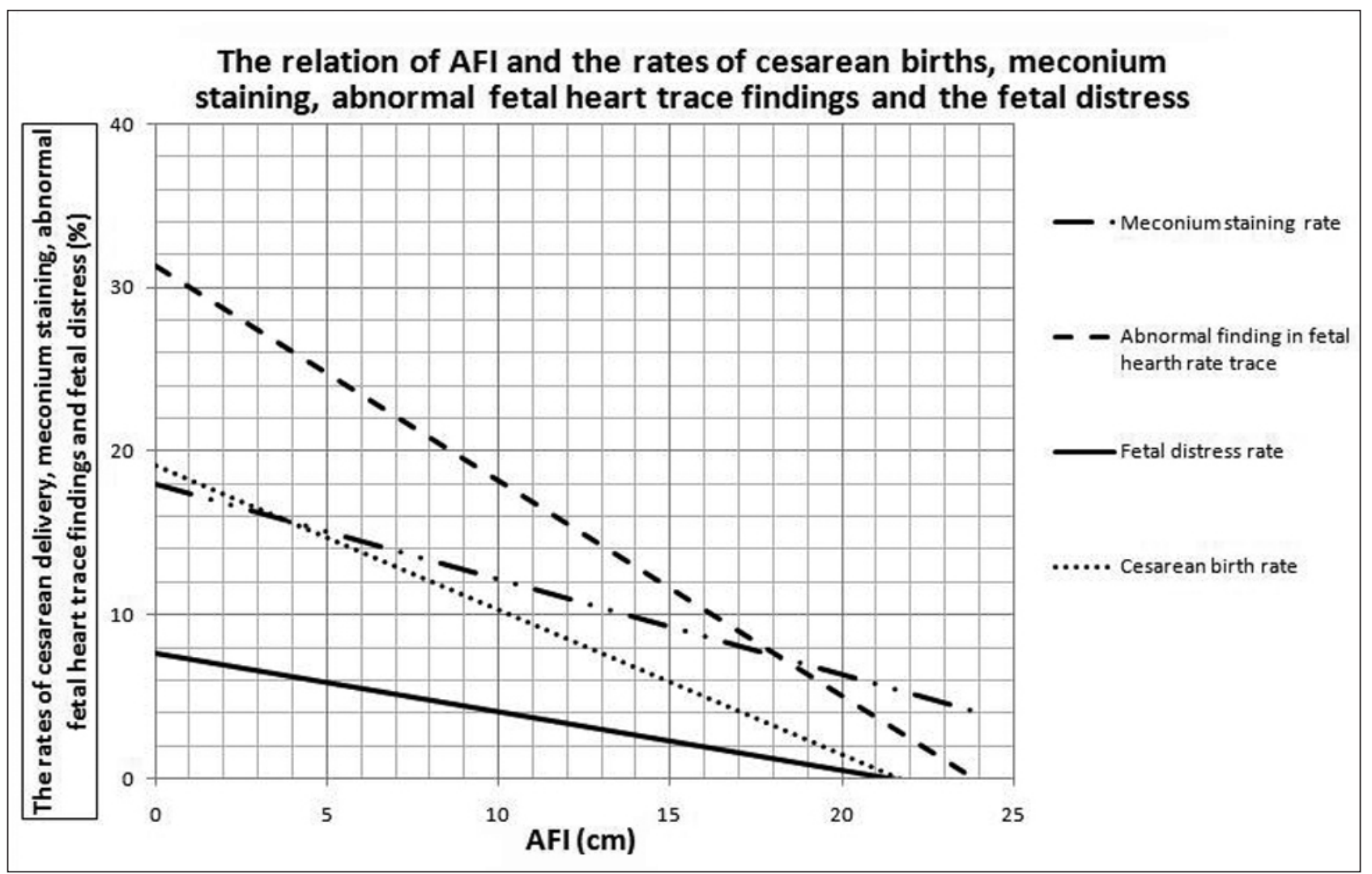

Figure 1. The relationship between AFI and the rates of cesarean births, meconium staining, abnormal fetal heart rate tracings, and fetal distress. AFI: Amniotic fluid index.

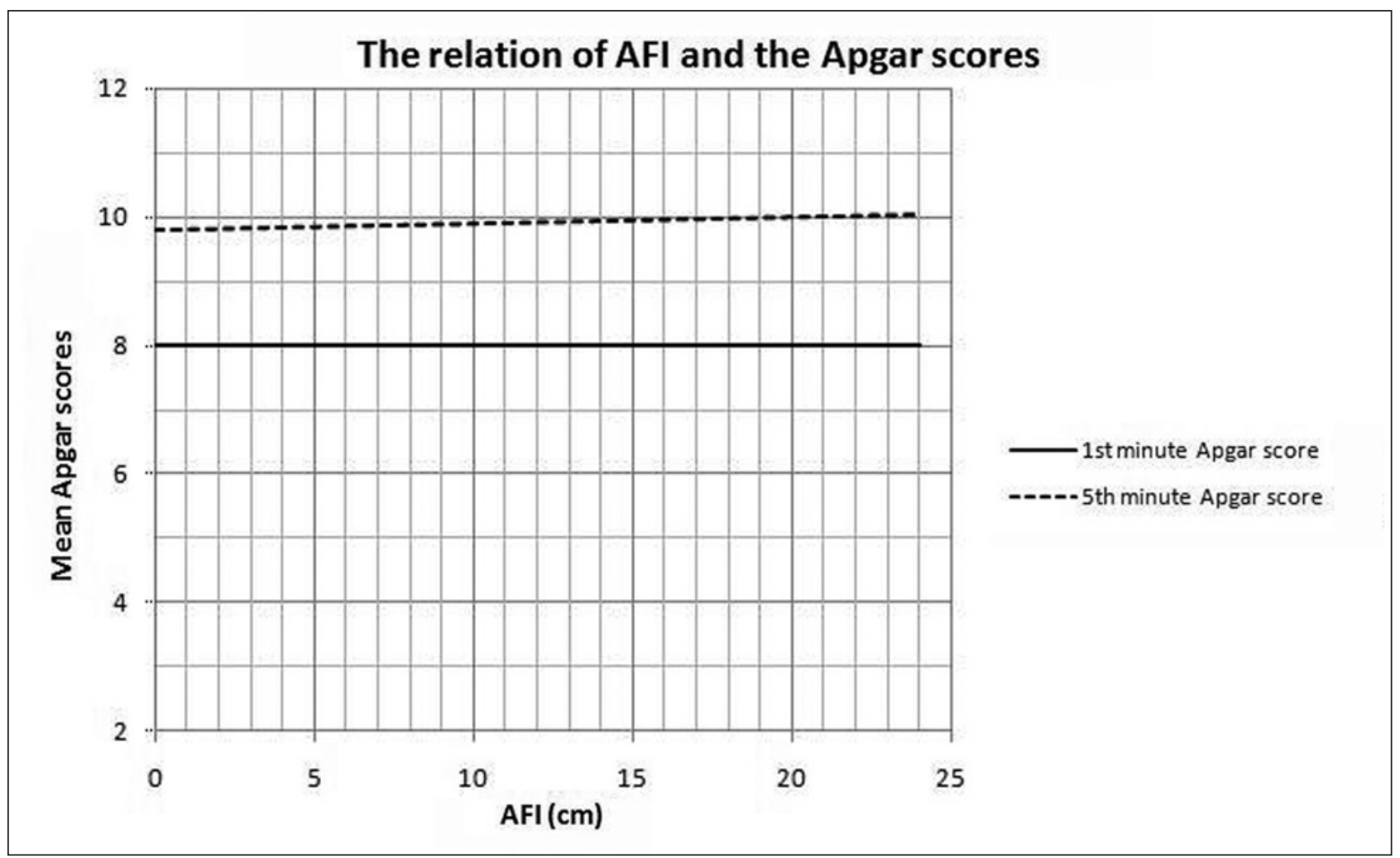

Figure 2. The relationship between AFI and Apgar scores. AFI: Amniotic fluid index. 
cesarean delivery rate, gestational week, abnormal fetal heart rate trace findings, meconium staining of the amniotic fluid, diagnosis of fetal distress, $5^{\text {th }}$ minute Apgar scores, and the post-date pregnancy rates.

Many authors signified high ratios of meconium staining with AFI measurements below $5,1 \mathrm{~cm} \cdot{ }^{3-5}$. However, Baron et al. did not find similar results and concluded that dissimilarities resulted from the high ratios of postterm pregnancies in the study populations of the other investigators. In our study, the ratio of meconium staining for any predicted oligohydramnios level was not significant. However, we observed meconium staining in 7 of $17(41 \%)$ of the pregnant women with gestations beyond 42 weeks. Meconium staining was observed in 74 of 683 (11\%) of the pregnant women who had a pregnancy of 42 weeks or less. This finding supports Baron et als'. account of their findings. Moreover, the ratios of pathological fetal heart rate findings and fetal distress indications for abdominal delivery were significantly higher in our study in the presence of meconium stained amniotic fluid.

Baron et al. were unable to find significant differences among their study groups when they studied the neonatal $1^{\text {st }}$ and $5^{\text {th }}$ minute Apgar Scores. Similarly, in our study, there were no differences observed in $1^{\text {st }}$ and $5^{\text {th }}$ minute Apgar Scores for any predicted AFI value. However, when we analyzed cesarean deliveries with an indication of fetal distress, we observed that 3 of 5 neonates $(60 \%)$ had $1{ }^{\text {st }}$ minute Apgar Scores below 7 in the $A F I \leq 3 \mathrm{~cm}$ group. We did not obtain the same correlation for the $5^{\text {th }}$ minute Apgar Scores.

In the study of Baron et al., hospital stay for neonates was longer in the oligohydramnios group, without any intra or post partum mortality. In our study, we could not observe any difference among groups for neonatal hospital stay and neonatal intensive care unit requirement. One neonate born with a congenital cardiac defect, with $1^{\text {st }}$ and $5^{\text {th }}$ minute Apgar Scores of 2 and 4, respectively, died on the first day of neonatal intensive care. There was no other fetal or neonatal death.

\section{Conclusion}

In low risk pregnancies, the severity of the decrease in $\mathrm{AFV}$, dependent/independent of gestational age, increases the ratios of pathological fetal heart rate trace findings, diagnosis of fetal distress, and the fetal distress indications which lead to cesarean deliveries. An AFI of $\leq 3 \mathrm{~cm}$ negatively influences the $1^{\text {st }}$ minute Apgar score. Finally, meconium stained amniotic fluid is more frequently associated with fetal distress, particularly in post term pregnancies.

\section{Conflict of interest}

We declare that we have no conflict of interest

\section{References}

1. Chamberlain PF, Manning FA, Morrison I, et al. Ultrasound evaluation of amniotic fluid volume. I.The relationship of marginal and decreased amniotic fluid volumes to perinatal outcome. Am J Obstet Gynecol 1984 ; 150: 245-9.

2. Murray $M$, editor. Antepartal fetal monitoring. In: Antepartal and Intrapartal Fetal Monitoring. New York : Springer Publishing Company; 2006:455-87.

3. Sarno AP Jr ,Ahn MO, Brar HS, et al. Intrapartum Doppler velocimetry, amniotic fluid volume, and fetal heart rate as predictors of subsequent fetal distress. Am J Obstet Gynecol 1989; 161:1508-14.

4. Sarno AP Jr,Ahn MO,Phelan JP. Intrapartum amniotic fluid volume at term; association of ruptered membranes, oligohydramnios and increased fetal risk. J Reprod Med 1990; 35:719-23.

5. Robson SC, Crawford RA, Spencer JAD, Lee A. Intrapartum amniotic fluid index and its relationship to fetal distress. Am J Obstet Gynecol 1992; 166:78-82.

6. Gümüş II, Köktener A, Turhan NO. Perinatal outcomes of pregnancies with borderline amniotic fluid index. Arch Gynecol Obstet 2007; 276:17-9.

7. Locatelli A, Vergani P, Toso L, et al. Perinatal outcome associated with oligohydramnios in uncomplicated term pregnancies. Arch Gynecol Obstet 2004; 269:130-3.

8. Creasy RK, Resnik R. Measurement of Fetal Activity. In: Richardson BS, Gagnon R, editors. Maternal Fetal Medicine. Philadelphia : W.B. Saunders Company; 1994:258-75.

9. Voxman EG, Tran S, Wing DA. Low Amniotic Fluid Index as a Predictor of Adverse Perinatal Outcome. Journal of Perinatology 2002; 22:282-5.

10. Morris JM, Thompson K, Smithey J, et al. The usefulness of ultrasound assessment of amniotic fluid in predicting adverse outcome in prolonged pregnancy: a prospective blinded observational study. Br J Obstet Gynaecol 2003; 110:989-94.

11. Phelan JP,Platt LD, Yeh S-Y, et al. The role of ultrasound assessment of amniotic fluid volume in the management of the postdate pregnancy. Am J Obstet Gynecol 1985; 151:304-8. 
12. Özden S, Zorsu S, Çetin A, et al. Clinical significance of the serial measurements of amniotic fluid volume in the prediction of fetal outcome in the post date pregnancies. $\mathrm{T}$ Klin J Gynecol Obst 1999; 9:22-6.

13. Hill LM, Breckle R, Wolfgram KR, et al. Oligohydramnios: Ultrasonically detected incidence and subsequent fetal outcome. Am J Obstet Gynecol 1983; 147:407-10.

14. Hoddick WK, Callen PW, Filly RA, et al. Ultrasonographic determination of qualitative amniotic fluid volume in intrauterin growth retardation: Reassessment of the $1 \mathrm{~cm}$ rule. Am J Obstet Gynecol 1984; 149:758-62.

15. Manning FA, Hill LM, Platt LD. Qualitative amniotic fluid volume determination by ultrasound: Antepartum detection of intrauterin growth retardation. Am J Obstet Gynecol 1981; 139:254-8.

16. Chauhan SP, Taylor M, Shields D, et al. Intrauterine growth restriction and oligohydramnios among high-risk patients. Am J Perinatol 2007; 24:215-21.

17. Gilbert WM. Disorders of Amniotic Fluid. In: Creasy RK, Resnik R. Maternal Fetal Medicine. Philadelphia : W.B. Saunders Company; 1994:620-24.

18. Alfirevic Z, Luckas M, Walkinshaw SA, et al. A randomised comparison between amniotic fluid index and maximum pool depth in the monitoring of post-term pregnancy. Br J Obstet Gynaecol 1997; 104:207-11.

19. Magann EF, Doherty DA, Field K, et al. Biophysical profile with amniotic fluid volume assessments.Obstet Gynecol 2004; 104:5-10.

20. Chauhan SP, Washburne JF, Magann EF, et al. A randomized study to assess the efficacy of the amniotic fluid index as a fetal admission test. Obstet Gynecol 1995; 86:9-13.

21. Moore TR, CayleJE. The amniotic fluid index in normal human pregnancy. Am J Obstet Gynecol 1990; 162:1168-73.

22. Baron C, Morgan MA, Gariti TJ. The impact of amniotic fluid volume assessed intrapartum on perinatal outcome. Am J Obstet Gynecol 1995; 173:167-74.

23. Moses J, Doherty DA, Magann EF, et al. A randomized clinical trial of the intrapartum assessment of amniotic fluid volume: amniotic fluid index versus the single deepest pocket technique. Am J Obstet Gynecol. 2004; 190:1564-70.

24. Phelan JP, Smith CV, Broussard P, et al. Amniotic fluid volume assessment with the four-quadrant technique at 3642 weeks' gestation. J Reprod Med 1987; 32:540-2.

25. Cunningham FG, MacDonald PC, Gant NF, et al, editors. Intrapartum Assesment. $19^{\text {th }}$ Ed. Williams Obstetrics. London: Appleton \& Lange (USA) - Prentice Hall International (UK) ; 1993:395-423.

26. Hadlock FP, Deter RL, Carpenter R, et al. Sonographhy of Fetal Urinary Tract Anomalies. AJR 1981; 137:261-7.

27. Driggers RW, Holcroft CJ, Blakemore KJ, et al. An Amniotic Fluid Index $\leq 5 \mathrm{~cm}$ within 7 Days of Delivery in the Third Trimester Is Not Associated with Decreasing Umbilical Arterial $\mathrm{pH}$ and Base Excess. Journal of Perinatology 2004; 24:72-6.
28. Jacoby HE. Amniotic Fluid Volumes. Develop. Med. Child Neurol 1966; 8:587-92.

29. Halperin ME, Fong KW, Zalev AH, et al. Reliability of amniotic fluid volume estimation from ultrasonograms: Intraobserver and interobserver variation before and after the establishment of criteria. Am J Obstet Gynecol 1985; 153:264-7.

30. Jeng $\mathrm{C}$, Jou $\mathrm{T}$, Wang $\mathrm{K}$, et al. Amniotic fluid index measurement with the four-quadrant technique during pregnancy. J Reprod Med 1990; 35:674-7. 